\title{
The Effect of Intergroup Contact in Gaming on Improving Empathetic Feelings and Reducing Stereotypes Towards Immigrants
}

\author{
Vivian Hsueh Hua Chen \\ Wee Kim Wee School of \\ Communication and Information, \\ Nanyang Technological University \\ chenhh@ntu.edu.sg
}

\author{
Wei Jie Dominic Koek \\ Graduate College, \\ Nanyang Technological University \\ koek0002@e.ntu.edu.sg
}

\author{
Gabrielle C. Ibasco \\ Wee Kim Wee School of \\ Communication and Information, \\ Nanyang Technological University \\ gabrielle.ibasco@ntu.edu.sg
}

\author{
Fidelia Beatrice \\ School of Social Sciences, \\ Nanyang Technological University \\ fide0004@e.ntu.edu.sg
}

\author{
Arul Chib \\ Wee Kim Wee School of \\ Communication and Information, \\ Nanyang Technological University \\ arulchib@ntu.edu.sg
}

\begin{abstract}
Video games have been designed and studied in the context of intergroup relations. Past studies have shown that overall gaming experience may induce empathy and reduce prejudice, however, the mechanism that leads to such an effect is not fully understood. The current study utilizes intergroup contact theory as a foundation to design a $2 D$ game that allows mediated contact to occur through hiring and dialogue choices. It examines how perceived positive vs. negative contact valence with outgroup immigrant workers influences empathetic feelings and stereotypes towards immigrants. Results showed that overall gameplay reduced negative stereotypes. Perceived positive contact predicts increased empathetic feelings and reduced negative stereotypes towards immigrants. However, there are no significant findings with regards to the influence of negative contact in the game. Implications and directions for further research are discussed.
\end{abstract}

\section{Introduction}

Interactive video games allow players to engage with social issues through game narrative and choices. Research has shown that video games have the potential to develop empathy among players [1]. Empathy is defined as "an other-oriented emotional response elicited by and congruent with the perceived welfare of someone else" [2, p. 419]. Players could experience empathy by taking the perspective of the game character. This could be achieved by reinforcing "similarities between themselves and characters in the game," which could trigger emotional responses to situations faced by another person [3, p. 10]. Experiencing interactions and storyline as a game character therefore can potentially enhance empathetic feelings towards culturally different others. The question is how interactions with characters in a computer-mediated video game environment can foster these prosocial outcomes.

Past literature based on the intergroup contact theory [4] has pointed to a viable direction. Intergroup contact has demonstrated effects on improving intergroup attitudes in different contexts such as racial or ethnic groups [5-7], gender [8], age [9], and religion [10]. Research has looked into the effect of mediated intergroup contact in digital environments. Most notably, studies have allowed people to work cooperatively or collaboratively with another outgroup through video games [11-13]. In one longitudinal intervention study, Palestinian and Jewish children experienced significant reductions in both intergroup stereotypes and negative emotions when they played the video game Minecraft cooperatively [11]. Stiff and Bowen [12] similarly had students from different universities engage in either cooperative or solo gameplay, and likewise found that self-reported attitudes toward the outgroup were more positive in the former condition.

However, the findings have not always been consistent. Simply sharing a task with an outgroup member, whether cooperative or competitive, may be equally effective in improving attitudes [14]. In one study, White participants were instructed to play an 
anagram game with a Black virtual character either collaboratively or competitively. Compared to the control condition, both conditions actually led to improvements in outgroup attitudes [14]. Earlier research outside of a video game context likewise found that competitive games with an outgroup member do not necessarily lead to a statistically significant increase in negative outgroup attitudes [15]. Moreover, while these studies enable co-action, where the participants work together to achieve an assigned goal, they do not study the direct intergroup interaction itself (i.e., through focused dialogues or conversations) and how people perceive the valence or quality of such an interaction.

Aside from the necessary conditions to facilitate intergroup contact, much attention has been given to the different components of intergroup contact, the quantity/frequency of contact, and the valence of contact (positive or negative). However, it is still unclear how the quality of intergroup contact relate to empathy and stereotypes toward outgroups, particularly in a computer-mediated environment. Therefore, a purpose-made game was employed in this study to examine how players' perceived computer-mediated contact quality through the various in-game scenarios were associated with their subsequent perceptions toward immigrants.

\section{Literature Review}

\subsection{Effects of gaming on perceptions toward immigrants}

Video game play can increase players' empathy $[16,17]$ and reduce prejudice toward outgroups $[12,18]$. Work by queer game developer Anne Anthropy, for example, aims to foster empathy toward the transgender community and experiences of dysphoria [19]. Peng and colleagues [20] also found that participants who played a serious game, relative to those who read text narratives, expressed greater willingness to help members of Darfuri residents in the game. In another paper, Boltz and colleagues [1] argued that Migrant Trail, a game where players could play either the role of migrants, or a border patrol officer recovering corpses in the desert, could encourage players to think from standpoints of game characters. These studies imply that parasocial interactions with outgroup members in video games could potentially influence one's intergroup attitudes.

However, the literature is scarce in empirically addressing how intergroup contact in video games can specifically improve empathy and attitudes. Breves [21] found that a brief verbal exchange with a Black nonplayable character (NPC) in a virtual reality (VR) port of Skyrim can improve explicit attitudes toward Black people. Indeed, contact with an outgroup NPC shows promise in shaping outgroup attitudes, as parasocial interactions with NPCs have been linked to a greater sense of presence or "being there" in an imaginary world $[22,23]$. Nonetheless, it is still unclear how parasocial contact with NPCs can influence intergroup bias in 2D games, which typically do not afford the same level of realism and immersion as the kind of VR technology utilized by Breves [21]. While Migrant Trail adopts role-playing to induce empathy, there is a lack of research investigating the effects of mediated intergroup contact in video games on attitudes toward immigrants.

Hence, the following research question is posed:

RQ1: How does parasocial intergroup contact with immigrant NPCs in a 2D serious game influence players' perceptions toward immigrants?

\subsection{Contact quality valence and prejudice}

Extending the intergroup contact theory, it has been found that the quality of contact with an outgroup member may be more important than the quantity of contact in influencing intergroup attitudes [24-26]. Many studies, however, examined the effect of positive contact versus the absence of contact [10, 27-29]. A few studies have found that when compared, negative contact increases prejudice, while positive contact plays a restorative role and decreases prejudice $[6,30]$.

Negative contact may lead to adverse effects on intergroup bias due to making group boundaries more salient [9]. In line with the basic tenets of social identity theory, people are motivated to ascribe positive traits to their own ingroup and negative traits to the outgroup $[31,32]$. As such, negative experiences with an outgroup may only serve to confirm or reify expectations that solidify stereotypical differences between an ingroup and outgroup [33]. Conversely, positive contact may provide counter-evidence to these negative expectations, reducing anxieties about intergroup interactions, and underscoring perceived ingroup and outgroup similarities. As such, negative contact may increase the salience of group distinctions in ways that positive contact does not [9].

The divergent outcomes of positive and negative contact have been found in the literature, though applications to mediated contact and interactive technology are scarce. According to a meta-analysis, positive contact in both direct and indirect forms can improve intergroup attitudes even outside of the lab setting [34]. Even the vicarious observation of a positive interaction between online poker players from different national groups online increases positive attitudes towards the outgroup. In this study, the reverse was also 
true, where witnessing negative interactions led to more negative attitudes towards the outgroup [30].

Within the contact quality dimension, some studies have also found that positive and negative contact valence may influence prejudice measures to a differential extent and through divergent mechanisms. However, results have been largely either mixed or derived from correlational designs with methodological limitations.

Firstly, research has found that negative contact may be more impactful and influential than positive contact in shaping outgroup attitudes [35, 36]. In a longitudinal study, Kotzur and Wagner [37] investigated how the rate of change in positive/negative contact experiences in Germany correlated with the rate of change in prejudice toward immigrants over time. Findings showed that negative contact significantly predicted stronger prejudice, while the opposite relationship was non-significant for positive contact. The authors thus speculate that negative contact experiences may hold a greater weight on outgroup impressions than positive contact experiences [37], as the former enhances the salience of group memberships. However, other research challenges this perceived asymmetry in magnitude between positive and negative contact effects, finding mixed or opposing results [38, 39]. In a study conducted in Iceland, Árnadóttir and colleagues [40] found that positive contact correlated with outgroup trust and orientation to a similar degree as negative contact. Instead, an interaction effect was discovered, whereby having extensive positive contact experiences in the past buffered against the effects of negative contact on prejudice.

Secondly, there is also some evidence that positive and negative contact may influence affective and cognitive dimensions of prejudice to a different extent [41]. Here, cognitive prejudice refers to negative stereotypes about an outgroup, while affective prejudice refers to one's emotions and feelings of affinity towards an outgroup. In a correlational study surveying White American undergraduates, Aberson [41] found that positive and negative contact was related to both affective and cognitive prejudice measures. However, negative contact predicted cognitive prejudice more strongly than positive contact did. This was explained by how, unlike affective prejudice, changes in cognitive prejudice may require a conscious awareness that an outgroup member is a part of an outgroup. Negative contact experiences, due to inducing high group category salience, reify latent stereotypes about an outgroup and perceptions of intergroup threat, thus more directly tapping into cognitive dimensions than positive contact [9]. These findings suggest that positive contact may not be the direct opposite of negative contact, as both may emphasize different underlying mechanisms.

However, Aberson's [41] findings may be, in part, due to the context in which intergroup contact experiences were studied. While negative contact was measured as the frequency of negative encounters with outgroup members generally, positive contact was operationalized as one's impressions of a close outgroup acquaintance that they know, thus priming participants to think about the outgroup member on an individuating, personal level [41]. This is problematic as the measure for negative contact was about the quantity of contact at the group level and the measure for positive contact was about subjective impressions at the individual level, which may trigger affective over cognitive dimensions of prejudice.

The present study therefore seeks to gain more insights on how positive vs. negative intergroup contact is related to intergroup perceptions by enabling mediated contact with outgroup immigrant characters in a video game. Instead of relying on impression recall, the game induces controlled, simulated contact experiences. The present study also operationalizes positive and negative contact consistently to give both constructs equal footing for comparison. In line with past research [11, 41, 42], we study the dual influences of intergroup contact on both empathic feelings (affective prejudice) and stereotypes (cognitive prejudice).

We propose the following hypotheses:

H1a: Perceived positive interactions with an outgroup non-playable character in a video game will positively predict empathic feelings towards the outgroup.

H1b: Perceived positive interactions with an outgroup non-playable character in a video game will negatively predict stereotypes towards the outgroup.

$\mathrm{H} 2 \mathrm{a}$ : Perceived negative interactions with an outgroup non-playable character in a video game will negatively predict empathic feelings towards the outgroup.

$\mathrm{H} 2 \mathrm{~b}$ : Perceived negative interactions with an outgroup non-playable character in a video game will positively predict stereotypes towards the outgroup.

H3a: There should be no difference in the magnitude by which perceived positive and negative interactions predict empathic feelings towards the outgroup.

H3b: There should be no difference in the magnitude by which perceived positive and negative interactions predict stereotypes towards the outgroup.

\section{Method}

\subsection{Game User Study Design}


A 2D video game was designed for this study. Players took on the role as a manager of the food establishment in the game, where they set up various food stalls, hired and managed workers. The distinction between ingroup and outgroup in this study is based on nationality. The NPC workers in the game were immigrants of various nationalities who came to the country to earn a living. The workers' nationalities were different from the participants'. Players were informed about the workers' nationalities through the text and color of their passports and facial features of the passport photos during the hiring phase. When they engaged in a dialogue with their workers, the color of the passport and the same passport photo were used to represent the worker. During the game, players interacted with the immigrant workers through various scenarios that required players to make decisions to either help or not help the workers (e.g., deciding if a particular worker should rush a food order for a customer). The game scenarios required either a positive or negative response that would have an impact on the workers' welfare, and these decisions would subsequently determine the quality of conversations (positive or negative).

A pre-post study design was used to examine how the game play influenced players' empathy toward immigrants. Participants first completed a pre-game questionnaire which measured their empathic concern toward immigrants and their demographic information, such as age, gender, and nationality. After three to five days, a link containing the video game was sent to participants through email. The entire gameplay lasted for approximately 20 to 25 minutes. After the game, participants completed a post-game questionnaire which measured their positive and negative emotions, which was used as an indicator toward players' quality of contact with the game characters, as well as their empathic concern toward immigrants.

\subsection{Participants}

A total of 81 participants were recruited through research recruitment channels on the messaging platform Telegram, in a university in Singapore. Participants were compensated with either S\$10 gift vouchers or course credits, upon completion of the study. The average age of participants was $23.16(\mathrm{SD}=$ $3.25)$, with 50 females $(61.7 \%)$ and 31 males $(38.3 \%)$. All of them were Singapore citizens. 25 of them reported a total household income of $\mathbf{S} \$, 000$ and above (30.7\%), 27 between $\mathrm{S} \$ 3,000$ to $\$ \$ 8,999$ (33.3\%), 14 below $\mathrm{S} \$ 3,000(17.3 \%)$, and 15 who did not know/refused to answer (18.5\%). In terms of average weekly game time, 15 of them play 7 hours or more (18.5\%), 19 between 3 to 7 hours (23.5\%), 37 play less than 3 hours (45.7\%), and 10 do not play video games $(12.3 \%)$.

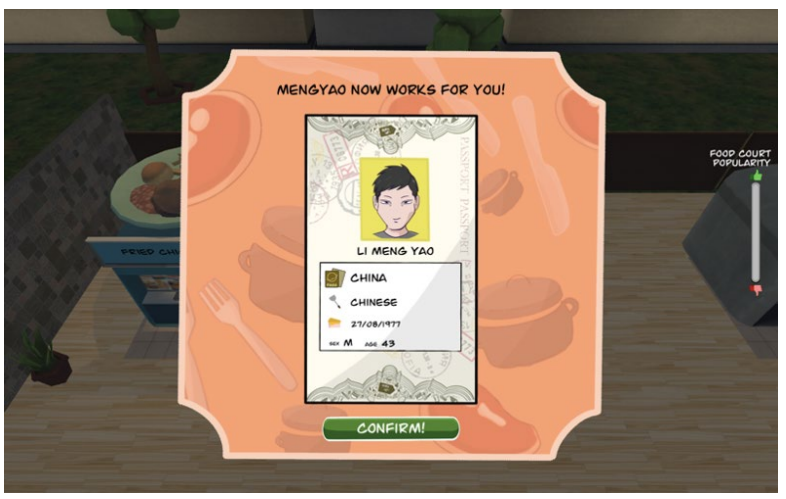

Figure 1. Workers' nationality reflected in their passports.

\subsection{Measures}

Empathic feelings toward immigrants were measured using adjectives adapted from Coke et al.'s [43] Emotional Response Questionnaire, validated by Batson et al. [44]. There were four adjectives, which included "sympathetic" and "moved" were measured on a seven-point Likert scale (1: Not At All; 7: Extremely). There were high reliability scores in both pre- $(\alpha=.88)$ and post-test $(\alpha=.93)$.

Stereotypes toward immigrants were measured using a semantic differential scale [45, 46]. The scale contained five pairs of opposite adjectives, such as "pleasant-unpleasant" and "good-bad", rated on a seven-point Likert scale (1: Positive; 7: Negative). High reliability scores were in both pre- $(\alpha=.92)$ and posttest $(\alpha=.94)$.

Perceived positive contact was measured using items adapted from Watson et al.'s [47] Positive and Negative Affect Schedule (PANAS). The three-item measures included adjectives such as "excited" and "enthusiastic", rated on a five-point Likert scale (1: Not At All/Very Slightly; 5: Extremely). A high reliability score was obtained $(\alpha=.89)$.

Perceived negative contact was also measured using adjectives adapted from Watson et al.'s [47] PANAS. The three-item measures comprised adjectives such as "nervous" and "upset, measured on a five-point Likert scale (1: Not At All/Very Slightly; 5: Extremely). A satisfactory reliability score was obtained $(\alpha=.83)$.

\subsection{Analysis \& Results}


Descriptive statistics of the main variables of interest were generated, prior to further analyses (Table $1)$.

A paired-samples $t$-test was performed to understand how players' empathy toward immigrants changed from pre- to post-game (RQ1). The analysis showed that the mean post-game empathy scores $(M=$ 3.93, $S D=1.38)$ were not significantly higher than the mean pre-game empathy scores $(M=3.92, S D=1.13)$, $\mathrm{t}(80)=-0.04, p=0.97$. The $95 \%$ confidence interval for the mean difference between the two scores ranged from -0.31 to 0.32 .

Table 1. Descriptive statistics

\begin{tabular}{|c|c|c|c|}
\hline Variable & $M(S D)$ & Min & Max \\
\hline Pre-Empathy & $3.93(1.13)$ & 1.00 & 6.00 \\
\hline Post-Empathy & $3.93(1.38)$ & 1.00 & 7.00 \\
\hline Pre-Stereotype & $3.32(0.99)$ & 1.00 & 6.20 \\
\hline Post-Stereotype & $3.07(1.03)$ & 1.00 & 5.80 \\
\hline Positive Affect & $2.03(1.02)$ & 1.00 & 4.67 \\
\hline Negative Affect & $1.47(0.73)$ & 1.00 & 4.00 \\
\hline
\end{tabular}

A paired-samples $t$-test was performed to understand how players' empathy toward immigrants changed from pre- to post-game (RQ1). The analysis showed that the mean post-game empathy scores $(M=$ $3.93, S D=1.38)$ were not significantly higher than the mean pre-game empathy scores $(M=3.92, S D=1.13)$, $\mathrm{t}(80)=-0.04, p=0.97$. The $95 \%$ confidence interval for the mean difference between the two scores ranged from -0.31 to 0.32 .

A multiple regression analysis was conducted to examine the relationship between players' post-game emotions and their empathic concern toward immigrants after the game play (H1a \& H1b). Players' pre-game empathy scores and demographic variables (age, gender, and game time) were first entered into the model as control variables, followed by their positive and negative affect scores in the second block.

The regression model that predicted players' postgame empathy scores was statistically significant, $R^{2}=$ 0.22 , adjusted $R^{2}=0.16, F(6,74)=3.55, p=.00$ (Table 2). Positive affect showed significant positive weights on post-empathy $(\beta=0.22,95 \% C I[0.02,0.59], p$ $=.04$ ), supporting H1a. However, H2a was not supported, as negative affect did not have any significant weights on post-empathy $(\beta=0.01,95 \% C I$ $[-0.39,0.43], p=.92)$.

Table 2. Multiple regression model to predict players' post-empathy toward immigrants

\begin{tabular}{|c|c|c|c|c|}
\hline Variable & $\boldsymbol{B}$ & $\boldsymbol{S E} \boldsymbol{\beta}$ & $\boldsymbol{p}$ \\
\hline Constant & 0.80 & 1.54 & n.s. \\
\hline $\begin{array}{c}\text { Pre- } \\
\text { Empathy }\end{array}$ & 0.42 & 0.13 & 0.34 & $* *$ \\
\hline Age & -0.01 & 0.05 & -0.01 & n.s. \\
\hline Gender & 0.41 & 0.34 & 0.14 & n.s. \\
\hline $\begin{array}{c}\text { Game Time } \\
\text { Gasitive }\end{array}$ & 0.09 & 0.08 & 0.12 & n.s. \\
\hline Affect & 0.02 & 0.20 & 0.01 & n.s. \\
\hline $\begin{array}{c}\text { Negative } \\
\text { Affect }\end{array}$ & 0.14 & 0.22 & $*$ \\
\hline$* p<.05, * *: p<.01, * * * p<.001$, n.s.: not significant
\end{tabular}

In order to examine how players' stereotypes toward immigrants changed from pre- to post-game, a paired-samples $t$-test was conducted (RQ1). The test indicated that the mean post-game stereotype scores $(M$ $=3.07, S D=1.03)$ were significantly lower than the mean pre-game stereotype scores $(M=3.31, S D=0.99)$, $t(80)=-2.29, p=.02$. The $95 \%$ confidence interval for the mean difference between the two scores ranged from -0.46 to -0.03 .

A multiple regression analysis was performed to understand the association between players' post-game affect and their stereotypes toward immigrants after playing the game (H2a \& H2b). Similarly, players' pregame stereotype scores and demographic variables (age, gender, and game time) were first entered into the model as control variables, followed by their positive and negative affect scores in the second block.

The regression model that predicted players' postgame stereotype scores was statistically significant, $R^{2}$ $=0.47$, adjusted $R^{2}=0.43, F(6,74)=10.85, p<.001$ (Table 3). Positive affect had significant negative 
weights on post-stereotypes $(\beta=-0.30,95 \% C I[-0.48$, 0.13 ], $p=0.00$ ), supporting H1b. However, negative affect did not show any significant weights on poststereotypes $(\beta=-0.15,95 \% C I[-0.46,0.04], p=0.10)$. Therefore, $\mathrm{H} 2 \mathrm{~b}$ failed to be supported.

Since perceived negative interactions did not significantly predict post-stereotypes, H3 failed to be supported.

Table 3. Multiple regression model to predict players' post-stereotypes toward immigrants

\begin{tabular}{|c|c|c|c|c|}
\hline Variable & $\boldsymbol{B}$ & $\boldsymbol{S E} \boldsymbol{B}$ & $\boldsymbol{\beta}$ & $\boldsymbol{p}$ \\
\hline Constant & 0.53 & 1.04 & n.s. \\
\hline $\begin{array}{c}\text { Pre- } \\
\text { Stereotypes }\end{array}$ & 0.59 & 0.09 & 0.56 & $* * *$ \\
\hline Age & 0.05 & 0.03 & 0.17 & n.s. \\
\hline $\begin{array}{c}\text { Gender } \\
\text { Agrect }\end{array}$ & 0.21 & 0.21 & 0.10 & n.s. \\
\hline $\begin{array}{c}\text { Game Time } \\
\text { Affect }\end{array}$ & -0.01 & 0.05 & -0.02 & n.s. \\
\hline $\begin{array}{c}\text { Negative } \\
\text { Affect }\end{array}$ & -0.21 & 0.13 & -0.15 & n.s. \\
\hline $\begin{array}{c}*: p<.05, * *: p<.01, * * *: p<.001, \text { n.s.: not } \\
\text { significant }\end{array}$ & 0.09 & -0.30 & $* *$ \\
\hline
\end{tabular}

\section{Discussion}

Results from this user study demonstrate the potential efficacy of video game narratives as a medium for intergroup contact. To answer RQ1, regardless of affect, players showed reduced stereotypes, but not increased empathetic feelings toward immigrants from pre- to post-gameplay. Extending past research on contact valence, we found that perceived contact quality can influence not just one, but multiple indicators of prejudice; namely, empathic feelings (affective) and stereotypes (cognitive). Perceived positive contact, measured directly after multiple interactions with various immigrant characters in the game, significantly predicted increased empathy and more positive stereotypes towards immigrants, controlling for baseline levels.
These findings are consistent with research that highlights how positive contact can reduce intergroup biases [48]. Only few studies have directly compared positive and negative contact as predictors $[6,30]$. Of these studies, the majority incorporated a crosssectional correlational design that required survey respondents to self-report their past intergroup contact experiences (see [27]), which may be susceptible to hindsight bias and social desirability effects. A few studies have manipulated contact valence directly through interactive media; however, these manipulations entailed vicarious rather than direct contact [30] or manipulated cooperation and competition as conditions [14, 49]. While related, cooperation and competition may not necessarily be equivalent constructs to positive and negative valence, respectively.

Accounting for these limitations, the present study operationalizes contact valence in terms of affect, an indirect measure of one's impressions directly following an interaction. Our findings thus support past research on prejudice and emotions. Negative perceptions of an outgroup can elicit negative emotions, such as anger, fear and disgust [50]. Emotions such as admiration and anger, likewise, have been found to mediate the effects of intergroup contact on prejudice towards ethnic outgroups [51]. Positive interactions with immigrant characters may have triggered positive feelings, which in turn, contributed to reduced prejudice at both the affective and cognitive level.

However, we did not find evidence to support $\mathrm{H} 2 \mathrm{a}$ and $\mathrm{H} 2 \mathrm{~b}$, which predicted an anti-parallel relationship between perceived negative contact and prejudice measures. This finding contradicts past research that found a negative relationship between negative contact experiences and prejudice $[35,36]$. Contact experiences based on existing relationships may trigger information about the outgroup member as an individual, rather than as an exemplar member of a group [52]. Research finds that past, extensive experiences with positive intergroup contact can buffer against the effects of negative contact in the present $[40,53]$. As our sample comprised of mostly young, college students in an international and multi-racial country, it is possible that they have already had positive interactions or existing relationships with immigrant outgroups to begin with. Negative encounters induced by the game may be viewed as negligible in comparison to these past experiences.

As negative affect did not significantly predict either of the prejudice measures, $\mathrm{H} 3 \mathrm{a}$ and $\mathrm{H} 3 \mathrm{~b}$ could not be properly tested or supported. It is possible that negative contact may have had a hidden effect on empathy and stereotypes, but not through inducing negative affect. As negative contact is theorized to enhance cognitive perceptions of intergroup boundaries 
[9], it is possible that negative contact may impact bias through cerebral rather than emotional mechanisms. The predictive strength of positive affect, however, provides further counter-evidence for the valence-effect asymmetry found in past research $[35,36,41]$. In line with other studies [39, 40], we contribute to the less pessimistic view that positive contact may play a bigger role than negative contact in shaping intergroup biases.

Further research should be conducted to investigate the absence of significant predictions for negative affect. Past research on negative contact required participants to recount their past experiences with a target outgroup in aggregate. These recounted real-life experiences may have a greater impact on perception than the relatively brief, fictional contact experiences with non-playable characters. The 2D video game medium may be limited in inducing social presence, the subjective sense that one is actually present with other people in a virtual environment $[54,55]$. A follow-up study could attempt making interactions appear more realistic by using more human-like avatars or human voiceovers, which can contribute to social presence [56]. Future research should compare how the role of contact valence plays out in different forms of interactive media, including $2 \mathrm{D}$ video games, $3 \mathrm{D}$ video games, and virtual reality environments, which vary in their capacity for immersion and realism.

Given that the perceived negative contact reported by participants was far below the mid-point of 2.50 on the five-point PANAS scale $(M=1.47 ; S D=0.73), t(80)$ $=-12.66, p<.001$, according to the one-sample $t$-test, perhaps a higher threshold of negativity should be implemented in the game dialogue. Manipulations of negative contact in past research incorporated more harsh dialogue or scenarios to induce a blatant impression of negativity. Andrews et al. [30], for instance, had participants in the negative condition witness a series of unpleasant exchanges between online poker players that consisted of personal insults and name-calling. In our game, dialogue between player characters and immigrant workers were not offensive or insulting. Even though workers' performance in the game has caused potential conflict, and their subsequent requests to the players via game dialogue may create discomfort, it might have provoked a relatively minor degree of negativity.

As an exploratory user study, this study has several limitations. This study was unable to completely control for the level of positivity and negativity that players experienced in their interactions, as these may also be dependent on the dialogue choices that players chose to make in response to prompts from the immigrant characters. The sample size of this user study was also relatively limited, making it difficult to generalize conclusions about affect and attitudes to other mediated contexts. We encourage more robust follow-ups to this preliminary study to determine whether predictive effects of both positive and negative affect exist in studies with greater statistical precision and power. As addressed earlier, future research should also consider proxies for perceived contact quality that go beyond affect, which may not fully capture the relationship between contact experiences and intergroup bias. While research has established a robust link between emotions and prejudice, we cannot necessarily rule out the possibility that affect could have also been shaped by factors other than intergroup contact, such as players' game choices, game control experience, visuals, audio, or even participants' mood on the day of gameplay.

\section{Conclusion}

The present study provides preliminary evidence for how the quality of perceived intergroup contact with non-playable characters in a $2 \mathrm{D}$ video game relate to intergroup perceptions. Despite the absence of significant effects found for perceived negative contact, other significant findings showed the effectiveness of the 2D game in improving intergroup perceptions. Serious video games may possibly be less at risk for inducing negative intergroup attitudes, and positive contact may be more likely. Innocuous dialogue may be sufficient to render positive emotions, and in turn, empathy and reduced stereotyping.

\section{Acknowledgments}

This research is supported by the Ministry of Education, Singapore, under its Academic Research Fund Tier 1 Grant (RG41/20).

\section{References}

[1] L. O. Boltz, D. Henriksen, and P. Mishra, "Rethinking technology \& creativity in the 21 st century: Empathy through gaming-perspective taking in a complex world," TechTrends, vol. 59, no. 6, pp. 3-8, 2015.

[2] C. D. Batson, N. Ahmad, D. A. Lishner, J. Tsang, C. Snyder, and S. Lopez, "Empathy and altruism," The Oxford handbook of hypo-egoic phenomena, pp. 161174, 2002.

[3] J. Belman and M. Flanagan, "Designing games to foster empathy," International Journal of Cognitive Technology, vol. 15, no. 1, p. 11, 2010.

[4] G. W. Allport, K. Clark, and T. Pettigrew, "The nature of prejudice," 1954.

[5] P. Dirksmeier, "Are urbanites more permissive? Germany's urban geography of prejudice," Urban Affairs Review, vol. 50, no. 6, pp. 835-863, 2014.

[6] R. Meleady, C. R. Seger, and M. Vermue, "Examining the role of positive and negative intergroup contact and 
anti-immigrant prejudice in B rexit," British Journal of Social Psychology, vol. 56, no. 4, pp. 799-808, 2017.

[7] U. Wagner, O. Christ, T. F. Pettigrew, J. Stellmacher, and C. Wolf, "Prejudice and minority proportion: Contact instead of threat effects," Social psychology quarterly, vol. 69, no. 4, pp. 380-390, 2006.

[8] M. Taschler and K. West, "Contact with counterstereotypical women predicts less sexism, less rape myth acceptance, less intention to rape (in men) and less projected enjoyment of rape (in women)," Sex Roles, vol. 76, no. 7-8, pp. 473-484, 2017.

[9] S. Paolini, J. Harwood, and M. Rubin, "Negative intergroup contact makes group memberships salient: Explaining why intergroup conflict endures," Personality and Social Psychology Bulletin, vol. 36, no. 12, pp. 1723-1738, 2010.

[10] J. R. Abrams, K. J. McGaughey, and H. Haghighat, "Attitudes toward Muslims: A test of the parasocial contact hypothesis and contact theory," Journal of Intercultural Communication Research, vol. 47, no. 4, pp. 276-292, 2018.

[11] J. Benatov, R. Berger, and C. T. Tadmor, "Gaming for peace: Virtual contact through cooperative video gaming increases children's intergroup tolerance in the context of the Israeli-Palestinian conflict," Journal of Experimental Social Psychology, vol. 92, p. 104065, 2021.

[12] C. Stiff and T. Bowen, "Two-player game: Playing casual video games with outgroup members reduces levels of prejudice toward that outgroup," International Journal of Human-Computer Interaction, vol. 32, no. 12, pp. 912-920, 2016.

[13] J. A. Velez, C. Mahood, D. R. Ewoldsen, and E. Moyer-Gusé, "Ingroup versus outgroup conflict in the context of violent video game play: The effect of cooperation on increased helping and decreased aggression," Communication Research, vol. 41, no. 5, pp. 607-626, 2014.

[14] M. H. Vang and J. Fox, "Race in virtual environments: Competitive versus cooperative games with black or white avatars," Cyberpsychology, Behavior, and Social Networking, vol. 17, no. 4, pp. 235-240, 2014.

[15] C. Silverthorne, G. Chelune, and A. Imada, "The effects of competition and cooperation on level of prejudice," The Journal of Social Psychology, vol. 92, no. 2, pp. 293-301, 1974.

[16] C. M. Bachen, P. F. Hernández-Ramos, and C. Raphael, "Simulating REAL LIVES: Promoting global empathy and interest in learning through simulation games," Simulation \& Gaming, vol. 43, no. 4, pp. 437460, 2012.

[17] C. M. Bachen, P. Hernández-Ramos, C. Raphael, and A. Waldron, "How do presence, flow, and character identification affect players' empathy and interest in learning from a serious computer game?," Computers in Human Behavior, vol. 64, pp. 77-87, 2016.

[18] C. Stiff and P. Kedra, "Playing well with others: The role of opponent and intergroup anxiety in the reduction of prejudice through collaborative video game play," Psychology of Popular Media, vol. 9, no. 1, p. 105, 2020.
[19] T. Pozo, "Queer games after empathy: Feminism and haptic game design aesthetics from consent to cuteness to the radically soft," Game Studies, vol. 18, no. 3, 2018.

[20] W. Peng, M. Lee, and C. Heeter, "The effects of a serious game on role-taking and willingness to help," Journal of Communication, vol. 60, no. 4, pp. 723-742, 2010.

[21] P. Breves, "Reducing Outgroup Bias through Intergroup Contact with Non-Playable Video Game Characters in VR," PRESENCE: Virtual and Augmented Reality, vol. 27, no. 3, pp. 257-273, 2020.

[22] S.-A. A. Jin, "Parasocial interaction with an avatar in second life: A typology of the self and an empirical test of the mediating role of social presence," Presence, vol. 19, no. 4, pp. 331-340, 2010.

[23] H. Schramm and T. Hartmann, "The PSI-Process Scales. A new measure to assess the intensity and breadth of parasocial processes," 2008.

[24] D. De Coninck, I. Rodríguez-de-Dios, and L. d'Haenens, "The contact hypothesis during the European refugee crisis: Relating quality and quantity of (in) direct intergroup contact to attitudes towards refugees," Group Processes \& Intergroup Relations, p. $1368430220929394,2020$.

[25] B. M. Johnston and D. E. Glasford, "Intergroup contact and helping: How quality contact and empathy shape outgroup helping," Group Processes \& Intergroup Relations, vol. 21, no. 8, pp. 1185-1201, 2018.

[26] S. Stathi, R. Guerra, G. A. Di Bernardo, and L. Vezzali, "Spontaneous imagined contact and intergroup relations: Quality matters," European Journal of Social Psychology, vol. 50, no. 1, pp. 124-142, 2020.

[27] J. Gu, I. Nielsen, J. Shachat, R. Smyth, and Y. Peng, "An experimental study of the effect of intergroup contact on attitudes in urban China," Urban Studies, vol. 53, no. 14, pp. 2991-3006, 2016.

[28] R. D. Maunder, F. A. White, and S. Verrelli, "Modern avenues for intergroup contact: Using E-contact and intergroup emotions to reduce stereotyping and social distancing against people with schizophrenia," Group Processes \& Intergroup Relations, vol. 22, no. 7, pp. 947-963, 2019.

[29] F. A. White, R. N. Turner, S. Verrelli, L. J. Harvey, and J. R. Hanna, "Improving intergroup relations between Catholics and Protestants in Northern Ireland via E-contact," European Journal of Social Psychology, vol. 49, no. 2, pp. 429-438, 2019.

[30] N. P. Andrews, K. Yogeeswaran, M. J. Walker, and M. Hewstone, "Effect of valenced vicarious online contact on out-group prejudice and perceived out-group variability: A study of online poker," Journal of Applied Social Psychology, vol. 48, no. 10, pp. 571581, 2018.

[31] M. B. Brewer, "The psychology of prejudice: Ingroup love or outgroup hate?," Journal of social issues, vol. 55, pp. 429-444, 1999.

[32] B. Mullen, R. Brown, and C. Smith, "Ingroup bias as a function of salience, relevance, and status: An integration," European journal of social psychology, vol. 22, no. 2, pp. 103-122, 1992. 
[33] P. J. Oakes, S. A. Haslam, and J. C. Turner, Stereotyping and social reality. Blackwell Publishing, 1994.

[34] G. Lemmer and U. Wagner, "Can we really reduce ethnic prejudice outside the lab? A meta-analysis of direct and indirect contact interventions," European Journal of Social Psychology, vol. 45, no. 2, pp. 152$168,2015$.

[35] F. K. Barlow et al., "The contact caveat: Negative contact predicts increased prejudice more than positive contact predicts reduced prejudice," Personality and Social Psychology Bulletin, vol. 38, no. 12, pp. 16291643, 2012.

[36] S. Graf, S. Paolini, and M. Rubin, "Negative intergroup contact is more influential, but positive intergroup contact is more common: Assessing contact prominence and contact prevalence in five Central European countries," European Journal of Social Psychology, vol. 44, no. 6, pp. 536-547, 2014.

[37] P. F. Kotzur and U. Wagner, "The dynamic relationship between contact opportunities, positive and negative intergroup contact, and prejudice: A longitudinal investigation," Journal of Personality and Social Psychology, vol. 120, no. 2, p. 418, 2021.

[38] C. L. Aberson and A. M. Gaffney, "An integrated threat model of explicit and implicit attitudes," European Journal of Social Psychology, vol. 39, no. 5, pp. 808-830, 2009.

[39] T. F. Pettigrew, L. R. Tropp, U. Wagner, and O. Christ, "Recent advances in intergroup contact theory," International journal of intercultural relations, vol. 35, no. 3, pp. 271-280, 2011.

[40] K. Árnadóttir, S. Lolliot, R. Brown, and M. Hewstone, "Positive and negative intergroup contact: Interaction not asymmetry," European Journal of Social Psychology, vol. 48, no. 6, pp. 784-800, 2018.

[41] C. L. Aberson, "Positive intergroup contact, negative intergroup contact, and threat as predictors of cognitive and affective dimensions of prejudice," Group Processes \& Intergroup Relations, vol. 18, no. 6, pp. 743-760, 2015.

[42] L. R. Tropp and T. F. Pettigrew, "Differential relationships between intergroup contact and affective and cognitive dimensions of prejudice," Personality and Social Psychology Bulletin, vol. 31, no. 8, pp. 1145-1158, 2005.

[43] J. S. Coke, C. D. Batson, and K. McDavis, "Empathic mediation of helping: a two-stage model," Journal of personality and social psychology, vol. 36, no. 7, p. 752, 1978.

[44] C. D. Batson, J. Fultz, and P. A. Schoenrade, "Distress and empathy: Two qualitatively distinct vicarious emotions with different motivational consequences," Journal of personality, vol. 55, no. 1, pp. 19-39, 1987.
[45] J. Dang, Z. E. Ekim, S. Ohlsson, and H. B. Schiöth, "Is there prejudice from thin air? Replicating the effect of emotion on automatic intergroup attitudes," $B M C$ psychology, vol. 8, pp. 1-6, 2020.

[46] C. E. Osgood, G. J. Suci, and P. H. Tannenbaum, The measurement of meaning (no. 47). University of Illinois press, 1957.

[47] D. Watson, L. A. Clark, and A. Tellegen, "Development and validation of brief measures of positive and negative affect: the PANAS scales," Journal of personality and social psychology, vol. 54, no. 6, p. 1063, 1988.

[48] T. F. Pettigrew and L. R. Tropp, "How does intergroup contact reduce prejudice? Meta-analytic tests of three mediators," European journal of social psychology, vol. 38, no. 6, pp. 922-934, 2008.

[49] J. Collange and J. Guegan, "Using virtual reality to induce gratitude through virtual social interaction," Computers in Human Behavior, vol. 113, p. 106473 , 2020.

[50] M. P. Tapias, J. Glaser, D. Keltner, K. Vasquez, and T. Wickens, "Emotion and prejudice: Specific emotions toward outgroups," Group Processes \& Intergroup Relations, vol. 10, no. 1, pp. 27-39, 2007.

[51] C. R. Seger, I. Banerji, S. H. Park, E. R. Smith, and D. M. Mackie, "Specific emotions as mediators of the effect of intergroup contact on prejudice: Findings across multiple participant and target groups," Cognition and emotion, vol. 31, no. 5, pp. 923-936, 2017.

[52] M. Rothbart, "Category-exemplar dynamics and stereotype change," International Journal of Intercultural Relations, vol. 20, no. 3-4, pp. 305-321, 1996.

[53] S. Paolini, J. Harwood, M. Rubin, S. Husnu, N. Joyce, and $\mathrm{M}$. Hewstone, "Positive and extensive intergroup contact in the past buffers against the disproportionate impact of negative contact in the present," European Journal of Social Psychology, vol. 44, no. 6, pp. 548$562,2014$.

[54] I. Ekman, G. Chanel, S. Järvelä, J. M. Kivikangas, M. Salminen, and N. Ravaja, "Social interaction in games: Measuring physiological linkage and social presence," Simulation \& Gaming, vol. 43, no. 3, pp. 321-338, 2012.

[55] B. E. Mennecke, J. L. Triplett, L. M. Hassall, and Z. J. Conde, "Embodied social presence theory," in 2010 $43 r$ Hawaii international conference on system sciences, 2010: IEEE, pp. 1-10.

[56] K.-M. Lee and C. Nass, "Social-psychological origins of feelings of presence: Creating social presence with machine-generated voices," Media Psychology, vol. 7, no. 1, pp. 31-45, 2005. 